\title{
Research on the Application of Blended Learning Model in Peasants Distance Education
}

\author{
Lei Chen ${ }^{1}$ Jianxin Guo ${ }^{1}$ \\ ${ }^{1}$ Institute of Information on Science and Technology of Agriculture, Beijing Academy of \\ agriculture and forestry Sciences. The Research Center of Beijing Engineering Technolo- \\ gy for Rural Remote Information Service
}

\begin{abstract}
It was more important to create a new training model to ensure the quality of distance education. From a peasant point of view, this paper thought that blended learning was an integration of face-toface learning and on-line learning. Based on Beijing rural modern distance education platform, the paper designed a new application for blended learning from the respects of training objective, training content, training organization, training process and training effect. So far, the study found that emphasis communication-activity, setting up effective technical support and improving the quality of training management had important effects for blended learning.
\end{abstract}

Keywords: distance education, peasants, blended learning, training model

\section{Introduction}

The essence of the peasants distance education is that the agricultural experts and peasants are separated. In order to remedy a drop in training quality what was caused by separation between experts and peasants, modern distance education creates a flexible training approach for peasants. This approach can make peasants learn anytime and anywhere. However, according to literature research and prac- tical investigation of modern peasants distance education, the authors found that it was more important to create a new training model suited to peasant learners to ensure the quality of training. Now the rural distance education training has been became an important way to develop rural human capital.

From a peasant point of view, this paper constructed a new training model based the theory of blended learning in the peasants distance education.

\section{The meaning of blended learning}

The concept of blended learning comes from the research of E-Learning and the discussion about "Walled does the university will be replaced by the university without bounding wall". According to the American ASTD Learning Circuits explanation, blended learning is a powerful training solution that combines e-learning with a variety of other delivery methods for a superior learning experience and a cost-effective approach that keeps organization at its peak-learning and achieving. Kedong Li professor thinks that blended learning is the reflection of E-Learning and a kind of teaching mode of improving the efficiency. Its main idea is to integrate face to face teaching and on-line learning mode and realize complementary advantages. 
Development of modern educational technology and educational theories is a spiraling trend. It has already gone through the traditional "passive learning" teaching mode to the constructivist theory "active learning" mode, and then developed into combination of blended learning mode. It has already achieved the sublimation of educational theories.

According to the existing research results, this paper thinks that blended learning is an integration of face-to-face classroom learning and e-learning based on information technology and has constituted a new learning environment. In this environment, it can bring the overall effect of the three components: classroom teaching, network teaching and practical application.

\section{Instructional design model of blended learning}

Based on Beijing rural modern distance education platform, the paper will analyze the application of blended learning (See Fig. 1).

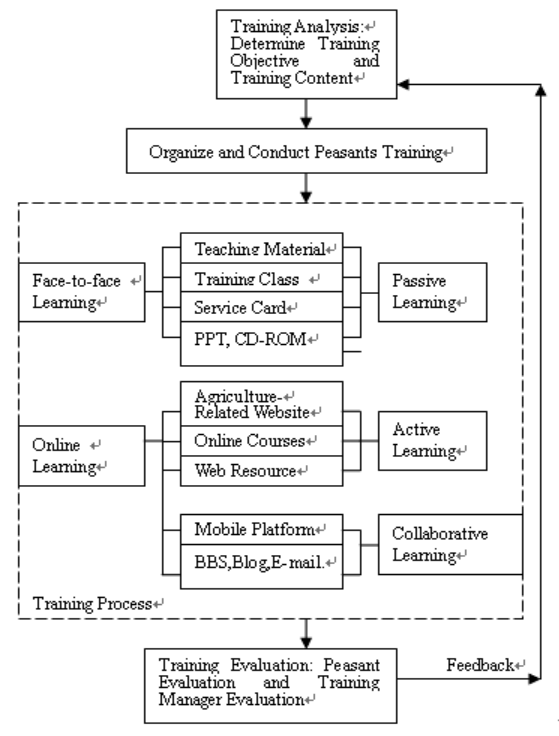

Fig. 1: Instructional design model of blended learning.

\subsection{Determine training objective and training content}

According to the Bloom's theory on Taxonomy of Educational Objectives for the Cognitive Domain, namely educational objective from low to high is divided into VI parts: knowledge, comprehension, application, analysis, synthesis and evaluation, the trainer should classify cognitive knowledge what peasants must currently learn and master. In the objective-making process, mutual relations between the total objective and objectives should be clear. Training objectives analysis will help to determine the order of the training content and select appropriate training methods.

By analyzing training content, the trainer can determine relative proportions of face-to-face and online learning.

Tab. 1: Analytical statement of face-to-face learning and online learning content

\begin{tabular}{|l|l|}
\hline Approach & Appropriate Training Content \\
\hline $\begin{array}{l}\text { Face-to- } \\
\text { face Learn- } \\
\text { ing }\end{array}$ & $\begin{array}{l}\text { Weak and uncertain learning mo- } \\
\text { tivation, Complicated science and } \\
\text { technology of agriculture, More } \\
\text { complex practices etc. }\end{array}$ \\
\hline $\begin{array}{l}\text { Online } \\
\text { Learning }\end{array}$ & $\begin{array}{l}\text { Strong learning motivation, Basic } \\
\text { knowledge of agriculture, } \\
\text { Demonstration of agricultural } \\
\text { basic skills, Rural policy and reg- } \\
\text { ulations, Basic law, Typical case } \\
\text { etc. }\end{array}$ \\
\hline
\end{tabular}

\subsection{Organize and conduct training}

Beijing rural modern distance education platform has provided independent learning space and abundant information resources for peasants. Training providers should strengthen the interaction between peasants and learning resources, by designing more effective forms of training organization and management. For example, the trainers impart training content to peasants, through the network, online video, multimedia CD-ROM and paper 
materials. The trainers help peasants learn by the website BBS, question-answering system and teaching platform etc.

\subsection{Design training process}

Blended learning theory determines that the mode of training part is divided into two parts, namely the face-to-face learning and online learning.

In developing the face-to-face learning process design, training managers can organize training courses by farmer field schools and "go to the countryside to teach". Training managers can also invite experts to on-the-spot investigation and field guidance, rely on basic agricultural technology personnel to spread fine variety with fine cultivating method, as well as issue teaching material, service card and study guide, etc.

In developing the online learning process design, training managers can carry out active learning by the distance education online courses, related agricultural website and network resources, or carry out collaborative learning through the distance education online communication platform and other live chat tool.

\subsection{Evaluate training effect}

The purpose of training effect evaluation lies in the realization degree of assessment training objective in the entire training process. Training effect evaluation includes both peasant evaluation and training manager evaluation. Peasant evaluation contains the recognition of blended learning mode and the utilization of network course resources, for example video learning duration, website return rate and platform interactive rate and so on. Training manager evaluation contains the rationality of training design and the adequacy of training content, for example designing training model, selecting training resources, organizing training work, etc. Training effect evaluation is the end of the training period but also a beginning of training cycle improvement.

\section{Actualization Guarantee}

The implementation of face-to-face learning relies on the level of interaction between peasant and trainer. It is necessary to build effective network learning platform for the implementation of online learning, including stable hardware facilities, rich software resources and highquality training managers.

\subsection{Emphasize communication- activity}

Training quality largely depends on the effect of communication between trainers and trainees. In order to improve the training effect, the trainers not only need to design training content and arouse the learners' enthusiasm, but also frequent interaction with learners in the course of blended learning. For example, the trainers should encourage peasants to discuss the daily agricultural production issues, then give prompt explanations and feedback, or carry out scene training in the fields and so on.

\subsection{Set up effective technical support}

The complicated network environment and high cost of distance education platform are widespread problems addressed in countryside. Stable and secured network environment is the first priority of developing distance education. To ensure the training system's maneuverability, technical support put emphasis on the development and application of a few key technologies. The application of mobile streaming media technology, customized technical support, resource delivery technology, as well as a variety of technolog- 
ical approaches will significantly enhance online learning effects.

\subsection{Improve the quality of training management}

At present, Beijing rural modern distance education platform has the model of "customized learning" and "decision-making support" being set up. It puts forward higher requirements on training managers. At first, the training managers have to master the technical architecture and software operating. Secondly, they will select and organize blended learning courses based on the characteristics of agricultural basics and sciences, as well as the standard of peasants' knowledge and learning habits. At last they should correctly guide peasants to make use of model of blended learning that is provided by them to create customized learning plans.

\section{Conclusions}

Beijing rural modern distance education platform officially launched in 2009. Until the end of Dec. 2012, 35,500 peasants registered as users and up to 4.09 million people have been trained. Platform video course clicks rose from 271,000 by the end of 2009 to 1.169 million by the end of 2012. The platform accumulative visit times increased from 319,000 by the end of 2009 to 29.949 million by the end of 2012. At present, Beijing rural distance education platform has the model of blended learning being set up.

With the improvement of instructional design, more and more customized learning plans have been generated based on blended learning. For peasants, the obvious advantage of the blended learning is that learning becomes a process, rather than an event. Blended learning puts training into the attractive environment, provides a forum for every learning style, includes reinforcement and coaching, and uses minimum effort and resources to gain maximum results.

\section{References}

[1] Yanfang Zhang, "Experiment research on the pattern design of blending learning in modern distance education," Qufu Normal University Master Degree Theses, 2007.

[2] Kim L.Niewolny, Patrick T.Lillard, "Expanding the boundaries of beginning farmer training and program development: A review of contemporary initiatives to cultivate a new generation of American farmers," Journal of Agriculture, Food Systems, and Community Development, pp.65-88, 2010.

[3] Wang Min, "Discussion on the Application of Blended Learning Model in Basic Accounting," Education and Teaching Research, pp. 94-94, Vol.26NO.2, 2012(2)

[4] Yang Jinshan,An Zhihong, "Research on Network Case Teaching Model Architecture Based on MultiLearning Model," Modern Computer, pp.150-152,2010(05)

[5] http://www.astd.org/Publications/Ne wsletters/ASTD-Links/ASTD-LinksArticles/2006/02/Blended-LearningWhy-Everything-Old-Is-New-Againbut-Better. 